\title{
Recent advances in triple negative breast cancer: the immunotherapy era
}

Antonio Marra ${ }^{1,2}$, Giulia Viale ${ }^{1,2}$ and Giuseppe Curigliano ${ }^{1,2^{*}}$

\begin{abstract}
Background: Several accomplishments have been achieved in triple-negative breast cancer (TNBC) research over the last year. The phase III IMpassion130 trial comparing chemotherapy plus atezolizumab versus chemotherapy plus placebo brought breast cancer into the immunotherapy era. Nevertheless, despite encouraging results being obtained in this trial, many open questions remain.

Main body: A positive overall survival outcome was achieved only in PD-L1+ TNBC patients, suggesting a need to enrich the patient population more likely to benefit from an immunotherapeutic approach. Moreover, it remains unknown whether single-agent immunotherapy might be a good option for some patients. In this context, the discovery and implementation of novel and appropriate biomarkers are required. Focusing on the early onset of TNBC, neoadjuvant trials could represent excellent in vivo platforms to test immunotherapy agents and their potential combinations, allowing the performance of translational studies for biomarker implementation and improved patient selection.
\end{abstract}

Conclusion: The aim of our review is to present recent advances in TNBC treatment and to discuss open issues in order to better define potential future directions for immunotherapy in TNBC.

Keywords: Triple-negative breast cancer, Immunotherapy, PD-L1, Biomarkers, Checkpoint inhibitors

\section{Background}

Triple-negative breast cancer (TNBC) accounts for approximately $15-20 \%$ of all breast carcinomas and is associated with earlier age of onset, aggressive clinical course, and dismal prognosis compared to hormone receptorand HER2-positive breast carcinomas [1]. Given the lack of effective treatments in this subtype of breast cancer, several efforts have been conducted in recent years to increase the therapeutic opportunities for TNBC patients.

Over the last 10 years, considerable evidence has highlighted the primary role of the immune system in influencing the disease course of TNBC. The presence of tumor-infiltrating lymphocytes (TILs), assessed by means of immunohistochemistry staining, is widely recognized as a predictor of good prognosis in both adjuvant and neoadjuvant settings of TNBC [2-5]. In addition, a deeper characterization of immune infiltrates, including the presence of a high number of cytotoxic $\left(\mathrm{CD}^{+}\right)$TILs or a high

\footnotetext{
* Correspondence: giuseppe.curigliano@ieo.it

'Division of Early Drug Development for Innovative Therapy, European Institute of Oncology (IEO), IRCCS, Milan, Italy

${ }^{2}$ Department of Oncology and Haematology, University of Milano, Milano, Italy
}

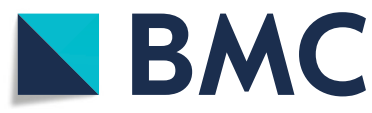

(c) The Author(s). 2019 Open Access This article is distributed under the terms of the Creative Commons Attribution 4.0 International License (http://creativecommons.org/licenses/by/4.0/), which permits unrestricted use, distribution, and reproduction in any medium, provided you give appropriate credit to the original author(s) and the source, provide a link to the Creative Commons license, and indicate if changes were made. The Creative Commons Public Domain Dedication waiver (http://creativecommons.org/publicdomain/zero/1.0/) applies to the data made available in this article, unless otherwise stated. better prognosis following neoadjuvant chemotherapy [6]. Along with the presence of TILs, the expression of immune evasion molecules in the tumor microenvironment, such as programmed death-ligand 1 (PD-L1), has also been shown to influence TNBC prognosis [7-10]. These data, together with the development of new therapeutic agents directed against immune checkpoint molecules, such as anti-PD-1 and anti-PD-L1 monoclonal antibodies, provide the rationale for the assessment of immunotherapeutic approaches in TNBC patients.

New and relevant evidence on the implementation of immune checkpoint-based treatments in TNBC has emerged over the last year, with the results of the IMpassion130 trial bringing breast cancer into the immunotherapy era. Schmid et al. [11] demonstrated a substantial overall survival (OS) benefit in patients with PD-L1-positive (PD-L1 ${ }^{+}$) metastatic or inoperable locally advanced TNBC through the addition of the anti-PD-L1 agent atezolizumab to first-line chemotherapy with nab-paclitaxel. Approximately $60 \%$ of the enrolled patients (451 for each treatment arm) experienced relapse after prior adjuvant/neoadjuvant treatment, while $37 \%$ presented with de novo stage IV disease. Additionally, 
approximately $41 \%$ of patients in the intent-to-treat (ITT) population had PD-L1 ${ }^{+}$disease. At a median follow-up of 12.9 months, the median progression-free survival (PFS) in the ITT population was significantly improved following the addition of atezolizumab as compared to chemotherapy alone (7.2 vs. 5.5 months); further, among the PD-L1 ${ }^{+}$ population, the respective PFS benefit was more pronounced (7.5 vs. 5.0 months). An interim OS analysis showed that the OS difference was not statistically significant in the ITT population (median OS, 21.3 months (atezolizumab + chemotherapy) vs. 17.6 months (chemotherapy alone)). However, a statistically significant median OS increase of 9.5 months was observed with the addition of atezolizumab in the $\mathrm{PD}-\mathrm{L}^{+}$population (25.0 vs. 15.5 months). Moreover, the objective response rate (ORR) was numerically higher following the addition of atezolizumab in both the ITT population (56\% vs. $46 \%)$ and the PD-L1 ${ }^{+}$ population (59\% vs. $43 \%$ ), and more complete responses were observed with atezolizumab than without (ITT, 7\% vs. $2 \%$; PD-L1 ${ }^{+}$population, $10 \%$ vs. $1 \%$ ).

The above data thus prompt the question of whether immunotherapy would truly be transformative for metastatic TNBC. Despite the encouraging results, various questions have arisen from the IMpassion130 trial, including how to appropriately assess tumors for PD-L1 expression given the benefits derived from atezolizumab treatment in this patient group, which companion diagnostic is the most suitable, whether PD-L1 should be tested on immune cells or tumor cells, whether nab-paclitaxel is the ideal chemotherapy partner for immune checkpoint inhibitors (ICIs), whether an atezolizumab monotherapy arm that might present a good option for a selected subset of patients was missed, or assessing what can be learnt from the neoadjuvant setting. The aim of the present review is to discuss these open questions in order to define potential future directions for immunotherapy in TNBC.

\section{How to enrich the TNBC population: PD-L1 and emerging biomarkers}

The positive results obtained in the $\mathrm{PD}-\mathrm{L}^{+}$subgroup in the IMpassion 130 trial suggest that there is a need to enrich the study population. However, PD-L1 is not the ideal biomarker to select patients for anti-PD1/PD-L1 therapies, as demonstrated in other cancers. Indeed, only a subset of patients with $\mathrm{PD}-\mathrm{L}^{+}$tumors derives a real clinical benefit from immunotherapeutic treatment, while these therapies can determine clinical and radiological responses also in $\mathrm{PD}-\mathrm{L}^{-}$cancers. Considering multiple parameters which take into consideration both tumor- and patient-related characteristics, a comprehensive view of immunotherapy in cancer treatment has been proposed and included in the framework of the cancer immunogram [12]. Given the potential toxicities of immunotherapy and the highly variable response across tumor types, as well as the significant economic burden of immunotherapeutic agents, the identification and implementation of novel biomarkers that can predict immunotherapeutic response are urgently required.

\section{PD-L1 expression}

PD-L1 expression on tumor cells and/or immune infiltrate cells is considered a useful biomarker of treatment response following anti-PD-1 or anti-PD-L1 therapies [13, 14]. PD-L1 assessment is indeed used as a predictive biomarker in other tumor types such as non-small cell lung cancer [15]. Nevertheless, considerable gaps remain in our knowledge of the technical aspects of this test, including the biologic implications and associations of PD-L1 expression, the dynamic changes in expression, the heterogeneity in expression on tumor cells and on immune cells, and prognostic and/or predictive implications [16].

PD-L1 expression in TNBC has been shown to range from 40 to $65 \%$ as tested, in most cases, in immune cells [7-10, 17]. In the IMpassion130 study, a PD-L1 expression above $1 \%$ in immune cells was used to define the PD- $\mathrm{L}^{+}$ group [11]. Interestingly, the majority of patients testing as $\mathrm{PD}-\mathrm{L}^{+}{ }^{+}$in immune cell tumors also had a positive PD-L1 expression on tumor cells [18]. In the Impassion130 biomarker subgroup analysis [18], PD-L1 expression on immune cells was positively correlated with $\mathrm{CD}^{+} \mathrm{T}$ cell number, and both factors were conjointly associated with increased PFS and OS. However, the best method to test PD-L1 expression in breast cancer should be harmonized. Since patients with PD-L1 $1^{-}$tumors may still obtain a clinical response with ICIs, PD-L1 expression should be used only to define a subgroup of patients expected to achieve greater benefit from ICIs rather than to exclude patients from treatment [19]. Nevertheless, this is certainly a provocative statement, underlined by the fact that more mature data from IMpassion130 and other trials with pembrolizumab in the same setting are still awaited in order to be able to draw final conclusions on this issue (Table 1). Therefore, a variety of potential biomarkers are now being assessed to predict immunotherapeutic efficacy in breast cancer beyond PD-L1 expression, including gene signatures, TILs, tumor mutational burden (TMB), microsatellite instability (MSI), and mismatch repair (MMR) deficiency.

\section{Tumor-infiltrating lymphocytes (TILs)}

TILs are a well-known prognostic factor in early-stage TNBC, positively correlated to both patient survival and pathological complete response after neoadjuvant chemotherapy [2-5]. In addition, TILs have shown a predictive value in patients with TNBC who were treated with ICI monotherapy, and their assessment is being implemented as a stratification factor in breast cancer immunotherapy trials [20]. As previously described, $\mathrm{CD}^{+}$TILs (together with PD-L1 expression on immune cells) have been 
Table 1 Ongoing phase II/III randomized immunotherapy trials in triple-negative breast cancer

\begin{tabular}{|c|c|c|c|c|c|}
\hline Setting & Trial & Phase & Regimen & Patients & Status \\
\hline \multirow[t]{4}{*}{ Neoadjuvant } & $\begin{array}{l}\text { NCT03639948 } \\
\text { (NeoPACT) }\end{array}$ & $\|$ & Carboplatin + docetaxel + pembrolizumab & 100 & $R$ \\
\hline & NCT03289819 & $\|$ & $\begin{array}{l}\text { Pembrolizumab }+ \text { Nab-paclitaxel } \rightarrow \text { pembrolizumab }+ \\
\text { epirubicin and cyclophosphamide }\end{array}$ & 50 & R \\
\hline & $\begin{array}{l}\text { NCT03356860 } \\
\text { (B-IMMUNE) }\end{array}$ & $\|$ & $\begin{array}{l}\text { Paclitaxel }+ \text { epirubicin }+ \text { cyclophosphamide } \pm \\
\text { durvalumab }\end{array}$ & 57 & R \\
\hline & $\begin{array}{l}\text { NCT02685059 } \\
\text { (GeparNuevo) }\end{array}$ & $\|$ & $\begin{array}{l}\text { Epirubicin }+ \text { nab-paclitaxel }+ \text { cyclophosphamide } \pm \\
\text { durvalumab }\end{array}$ & 174 & ANR \\
\hline \multirow[t]{3}{*}{ Neoadjuvant/Adjuvant } & $\begin{array}{l}\text { NCT03036488 } \\
\text { (KEYNOTE-522) }\end{array}$ & III & $\begin{array}{l}\text { Carboplatin }+ \text { paclitaxel }+ \text { (anthracycline) }+ \\
\text { cyclophosphamide } \pm \text { pembrolizumab } \rightarrow \text { pembrolizumab }\end{array}$ & 1174 & ANR \\
\hline & NCT03281954 & III & $\begin{array}{l}\text { Doxorubicin }+ \text { cyclophosphamide }+ \text { paclitaxel }+ \\
\text { carboplatin } \pm \text { atezolizumab } \rightarrow \text { atezolizumab }\end{array}$ & 1520 & $\mathrm{R}$ \\
\hline & $\begin{array}{l}\text { NCT03197935 } \\
\text { (IMpassion031) }\end{array}$ & III & $\begin{array}{l}\text { Doxorubicin }+ \text { cyclophosphamide }+ \text { nab-paclitaxel } \pm \\
\text { atezolizumab } \rightarrow \text { atezolizumab }\end{array}$ & 204 & ANR \\
\hline \multirow{2}{*}{$\begin{array}{l}\text { Adjuvant only for patients with residual disease } \\
\text { after neoadjuvant chemotherapy }\end{array}$} & NCT02954874 & III & Pembrolizumab vs. observation & 1000 & R \\
\hline & NCT03756298 & $\|$ & Capecitabine \pm atezolizumab & 284 & $\mathrm{R}$ \\
\hline \multirow[t]{2}{*}{ Adjuvant } & $\begin{array}{l}\text { NCT03498716 } \\
\text { (IMpassion030) }\end{array}$ & III & $\begin{array}{l}\text { Paclitaxel } \rightarrow \text { dose-dense doxorubicin/epirubicin }+ \\
\text { cyclophosphamide } \pm \text { atezolizumab }\end{array}$ & 2300 & R \\
\hline & $\begin{array}{l}\text { NCT02926196 } \\
\text { (A-Brave) }\end{array}$ & III & Avelumab vs. observation & 335 & R \\
\hline \multirow[t]{14}{*}{ Locally advanced or metastatic TNBC } & NCT02768701 & $\|$ & Cyclophosphamide + pembrolizumab & 40 & ANR \\
\hline & NCT03121352 & $\|$ & Carboplatin, nab-paclitaxel and pembrolizumab & 30 & R \\
\hline & $\begin{array}{l}\text { NCT02819518 } \\
\text { (KEYNOTE-355) }\end{array}$ & III & $\begin{array}{l}\text { Abraxane or paclitaxel or carboplatin/gemcitabine } \pm \\
\text { pembrolizumab }\end{array}$ & 858 & ANR \\
\hline & $\begin{array}{l}\text { NCT02555657 } \\
\text { (KEYNOTE-119) }\end{array}$ & III & $\begin{array}{l}\text { Capecitabine, eribulin, gemcitabine, or vinorelbine } \\
\text { as TPC vs. pembrolizumab }\end{array}$ & 600 & ANR \\
\hline & NCT03644589 & $\|$ & Cisplatin + pembrolizumab & 60 & NYR \\
\hline & NCT02755272 & $\|$ & Carboplatin + gemcitabine \pm pembrolizumab & 87 & $\mathrm{R}$ \\
\hline & $\begin{array}{l}\text { NCT02447003 } \\
\text { (KEYNOTE-086) }\end{array}$ & $\|$ & Pembrolizumab monotherapy & 285 & ANR \\
\hline & $\begin{array}{l}\text { NCT03125902 } \\
\text { (IMpassion131) }\end{array}$ & III & Paclitaxel \pm atezolizumab & 540 & R \\
\hline & $\begin{array}{l}\text { NCT03164993 } \\
\text { (ALICE) }\end{array}$ & $\|$ & $\begin{array}{l}\text { Pegylated liposomal doxorubicin }+ \text { cyclophosphamide } \pm \\
\text { atezolizumab }\end{array}$ & 75 & R \\
\hline & NCT03206203 & $\|$ & Carboplatin + gemcitabine & 185 & R \\
\hline & NCT03606967 & $\|$ & Nab-paclitaxel + durvalumab \pm neoantigen vaccine & 70 & NYR \\
\hline & $\begin{array}{l}\text { NCT03616886 } \\
\text { (SYNERGY) }\end{array}$ & $\|$ & Paclitaxel, carboplatin, durvalumab \pm oleclumab & 171 & R \\
\hline & $\begin{array}{l}\text { NCT03371017 } \\
\text { (IMpassion132) } \\
\text { (early recurrent) }\end{array}$ & III & $\begin{array}{l}\text { Carboplatin }+ \text { gemcitabine or capecitabine } \pm \\
\text { atezolizumab }\end{array}$ & 350 & R \\
\hline & $\begin{array}{l}\text { NCT03167619 } \\
\text { (DORA) }\end{array}$ & $\|$ & Durvalumab + olaparib & 60 & R \\
\hline
\end{tabular}

ANR active, not recruiting, NYR not yet recruiting, TPC therapy per physician's choice, $R$ recruiting

associated with increased PFS and OS in patients treated with atezolizumab and nab-paclitaxel in the IMpassion 130 trial [18]. Conversely, stromal TILs were only able to predict PFS benefit. In this context, interesting findings have been provided by preliminary analyses of the KEYNOTE-173 trial [21], which is investigating the combination of pembrolizumab and chemotherapy in the neoadjuvant setting of TNBC. A recent exploratory analysis of this trial showed that high levels of pretreatment stromal TILs and PD-L1 expression, reported as a combined positive score, were significantly associated with higher pathologic complete response and overall response rates in TNBC patients treated with an immunotherapy-based combination [21]. 
Moreover, recent evidence has suggested that qualitative differences in a TIL subpopulation can better define patient prognosis [22]. $\mathrm{CD}^{+} \mathrm{T}$ cells with features of tissue-resident memory $\mathrm{T}$ cell differentiation were described in the lymphocytic infiltrate from breast tumors; the $\mathrm{CD}^{+}$ tissue-resident memory gene signature subsequently developed was shown to be significantly associated with improved patient survival in early-stage TNBC [22].

\section{Gene signatures}

In conjunction with TILs, multiple gene signatures have been studied as surrogates of breast cancer immunogenicity. A recent proposal classified breast cancer into four categories (immunologic constants of rejection (ICR) ICR1 through ICR4) according to their immune-related gene expressions, with these categories being correlated with survival in a retrospective in silico simulation [23]. Specifically, the T helper 1 phenotype (ICR4), associated with an upregulation of immunoregulatory transcripts such as PD-L1, PD-1, FOXP3, IDO1, and CTLA-4, was correlated with a prolonged patient survival. Conversely, the presence of MAPK pathway disruptions was tightly associated with an immune-unfavorable phenotype (ICR1), suggesting that alterations in this pathway are linked to a negative regulation of immune response in breast cancer. Interestingly, inhibition of MEK, a crucial molecule of the MAPK pathway, was able to increase PD-L1 and MHC class I expression on TNBC cells, synergizing with PD-L1/PD-1 inhibition in inducing antitumor immune responses in TNBC mouse models [24]. In a further study, a four-gene signature (HLF, CXCL13, SULT1E1, and GBP1) was found to predict an increased number of TILs and an improved disease-free survival in early stage TNBC [25]. However, these gene signatures have not yet been tested in metastatic TNBC patients and their role in predicting response to ICIs remains to be defined.

\section{Tumor mutational burden (TMB)}

A high TMB has been associated with immunogenicity in several tumor types [26] and correlated with clinical response and increased survival after ICI-based immunotherapy in patients with melanoma, lung, and colorectal cancers [27-30]. TMB is a measurement of the number of nonsynonymous mutations carried by tumor cells [27]. Mutations lead to increased expression of neoantigens in the context of $\mathrm{MHC}$ class I antigens, enhancing the recognition of cancer cells by $\mathrm{T}$ cells. However, limited data regarding TMB in breast cancer is available. From genomic data, patients with a favorable immune subclass (based on 'positive' immune-infiltrate disposition) along with a high TMB have a better prognosis [31]. In addition, a higher TMB is more frequent in TNBC as compared to hormone receptor-positive subtypes [31]. In contrast with these findings, Samstein et al. [30] recently published a wide analysis of clinical and genomic data from more than 1600 advanced cancer patients treated with ICIs, and reported no significant differences for breast cancer patients in terms of survival after immunotherapy treatment. In order to reconcile these discrepancies, we presume that a high TMB alone does not represent the optimal predictor for immunotherapeutic response in breast cancer, suggesting that a finer selection to enrich the TNBC patient population is required.

\section{MSI and MMR deficiency}

Microsatellites are tandem repeats of short DNA sequences, abundant throughout the human genome. MSI is a hypermutator phenotype that occurs in some tumors with an impaired DNA MMR [32]. MMR deficiency is known to occur in some tumors, either by somatic hypermutation of MMR genes, an inherited germline MMR pathway mutation, or double somatic mutations in MMR genes [33]. Recently, tumors harboring a high MSI have been found to be susceptible to ICI-based immunotherapy [34, 35], leading to the approval of the anti-PD-1 agent pembrolizumab for any high MSI or MMR-deficient unresectable or metastatic solid tumor. MSI incidence in breast cancer has not yet been fully elucidated, although high MSI in breast cancers seems to be found in less than $2 \%$ of cases [32]. In a large analysis of more than 1900 breast cancers [36], high-MSI tumors presented a low incidence $(0.6 \%)$; however, a conjoined analysis of PD-L1 expression, high TMB, and high MSI selected up to $13 \%$ of TNBC patients with at least one of these alterations. Considering that approximately $5 \%$ of unselected patients with breast cancer carry a germline BRCA mutation [37], BRCA1 mutations are predisposed to TNBC, being discovered in 40-50\% of cases [38]. Given the central role of BRCA1 in homologous recombination-mediated DNA repair [39], BRCA1-mutated TNBC showed a higher somatic mutational load, a greater number of TILs, and an increased expression of immunomodulatory genes (PD-1 and CTLA-4) as compared to BRCA1-wildtype TNBC [40]. Interestingly, the combination of two ICIs (against PD-1 and CTLA-4, respectively) with cisplatin treatment attenuated growth and improved survival in an in vivo BRCA1-deficient TNBC model, providing a rationale to implement immunotherapeutic strategies in this subgroup of TNBC. Several clinical trials are testing a combination of ICIs and PARP inhibitors (e.g., olaparib, niraparib, and talazoparib) with preliminary data of activity $[41,42]$.

\section{Choosing the right chemotherapeutic partner for immunotherapy}

Despite assessments regarding the ideal chemotherapeutic partner for combination treatment with ICIs, various 
questions remain. Nab-paclitaxel was initially selected in the IMpassion130 study because it facilitates the reduced use of corticosteroids [43]. However, better agents may be available to enhance immunogenicity of breast cancer, including anthracyclines, platinum salts, and other taxanes [44]. Chemotherapy can induce multiple immunomodulatory changes in the tumor microenvironment, including increased antigen release by tumor cells, PD-L1 upregulation, and hyperexpression of immunogenic cell surface markers (e.g., MHC class I). Collectively, these modifications might positively influence the effectiveness of immunotherapy $[45,46]$. Specifically, various chemotherapeutic drugs routinely adopted for TNBC treatment can induce distinct effects on the immune system, as described in detail below.

\section{Anthracyclines}

Anthracyclines are capable of inducing immunogenic cell death (ICD), a form of apoptosis which can induce an effective antitumor immune response through activation of dendritic cells and specific $\mathrm{T}$ cell response [47]. In addition, anthracyclines can also increase proliferation of $\mathrm{CD}^{+} \mathrm{T}$ cells.

\section{Taxanes}

Taxanes can increase TIL recruitment in primary breast cancer [48]. Moreover, taxanes have been shown to selectively decrease $\mathrm{T}$ regulatory and myeloid-derived suppressor cells (MDSCs), partially reducing immunosuppression in the tumor microenvironment [49-51]. We have to highlight that these immunomodulating effects have been described for old generation taxanes (docetaxel and paclitaxel); no preclinical data regarding nab-paclitaxel's activity on the immune system have been reported so far.

\section{Cyclophosphamide}

Cyclophosphamide, in conjunction with its well-known ability to induce ICD, can suppress $\mathrm{T}$ regulatory cells and increase the proliferative capacity of $\mathrm{CD}^{+} \mathrm{T}$ cells and natural killer cells $[52,53]$.

\section{Gemcitabine}

Gemcitabine can reduce MDSC number and increase the anti-tumor activity of $\mathrm{CD}^{+} \mathrm{T}$ cells $[54,55]$.

\section{Platinum salts}

Platinum salts have been shown to induce ICD as well as to increase MHC class I complex on tumor cells [56, 57], also promoting $\mathrm{T}$ cell activation and downregulating MDSC function [58].

\section{Single agent versus combination immunotherapy in TNBC}

In addition to the results of the IMpassion130 study [11], other clinical trials are currently evaluating chemotherapy and immunotherapy combinations in TNBC patients. Preliminary data are available for the open-label phase Ib/II KEYNOTE-150 trial assessing the combination of eribulin and pembrolizumab [59]. Among 107 metastatic TNBC patients (106 evaluable for efficacy), 65 were treatment naïve, while 41 had received one to two prior lines of therapy. Half of the patients in the study had PD-L $1^{+}$TNBC $(45.8 \%)$. The ORR of the combination treatment in the overall population and that in the untreated and pretreated patients was $26.4,29.2$, and $22.0 \%$, respectively. Clinical activity was observed regardless of PD-L1 expression (ORR $30.6 \%$ for PD-L1 ${ }^{+}(n=49)$ and $22.4 \%$ PD-L1 ${ }^{-}$ $(n=49))$, even if a greater number of responses was reported in the PD- $\mathrm{L}^{+}$subgroup. The PFS and OS across the full study were 4.2 and 17.7 months, respectively. In the first-line and second-/third-line settings, the median PFS was 4.9 and 4.1 months, respectively, while the median OS was 17.7 and 18.3 months. Considering that KEYNOTE-150 was a single-arm phase Ib/II trial, the results are largely comparable with those obtained from the IMpassion130 study.

While the combinations of atezolizumab with nab-paclitaxel and pembrolizumab with eribulin produced substantial benefits in TNBC patients, we hypothesize that some subgroups of breast cancer patients (e.g., those with high TILs or high PD-L1 expression) may derive benefit from ICI monotherapy; evidence of this is available from phase I/II clinical trials (Table 2).

In a phase I clinical trial [63], atezolizumab led to a higher ORR in the first-line setting (24\%) compared to a second-line or greater setting (6\%). In first-line patients, median OS was 17.6 months. Interestingly, patients with PD-L1 expression in at least $1 \%$ of tumor-infiltrating immune cells had higher ORRs (12 vs. 0\%) and a longer OS (10.1 vs. 6.0 months) than those with PD-L1 expression in less than $1 \%$ of tumor-infiltrating immune cells. High levels of immune cells (>10\%) were independently associated with higher ORR and longer OS.

In the phase Ib KEYNOTE-012 trial [60], the anti-PD-1 agent pembrolizumab achieved an ORR of $18.5 \%$ in metastatic TNBC patients, with a median OS of 11.2 months. Of note, $15.6 \%$ of the subjects enrolled in this trial were treatment naive. Similarly, in the phase II trial KEYNOTE-086 (cohort-A) [61], pembrolizumab led to an ORR and disease control rate of 5.3 and $7.6 \%$, respectively, in pretreated TNBC patients; median PFS and OS were 2.0 and 9.0 months, respectively. Patients with PD-L1 ${ }^{+}$tumors showed only a slight increase in response rate. Additionally, approximately $40 \%$ of patients received more than three lines of therapy for metastatic disease. 
Table 2 Completed studies with immune checkpoint inhibitors in triple-negative breast cancer

\begin{tabular}{|c|c|c|c|c|c|}
\hline Trial & Setting & Drug & Patients & Results & Ref. \\
\hline \multicolumn{6}{|c|}{ Single agent immunotherapy } \\
\hline $\begin{array}{l}\text { KEYNOTE-012 } \\
\text { NCT01848834 }\end{array}$ & Advanced PD-L1 $1^{+}$TNBC & Pembrolizumab 10 mg/kg Q2W & 27 & $\begin{array}{l}\text { ORR, } 18.5 \% \\
\text { Median PFS, } 1.9 \text { months } \\
\text { Median OS, } 11.2 \text { months }\end{array}$ & [60] \\
\hline $\begin{array}{l}\text { KEYNOTE-086 } \\
\text { NCT02447003 }\end{array}$ & $\begin{array}{l}\text { Advanced, untreated, any PD-L1 } \\
\text { TNBC (cohort A) } \\
\text { Advanced, untreated PD-L1 }{ }^{+} \\
\text {TNBC (cohort B) }\end{array}$ & Pembrolizumab 200 mg Q3W & $\begin{array}{l}\text { Cohort A: } 170 \\
\text { Cohort B: } 84\end{array}$ & $\begin{array}{l}\text { ORR Cohort A, } 4.7 \% \\
\text { ORR Cohort B, 22.6\% } \\
\text { Median PFS Cohort A, } \\
2 \text { months } \\
\text { Median PFS Cohort B, } \\
2.1 \text { months } \\
\text { Median OS Cohort A, } \\
8.9 \text { months } \\
\text { Median OS Cohort B, } \\
19.2 \text { months }\end{array}$ & $\begin{array}{l}{[20,} \\
61]\end{array}$ \\
\hline $\begin{array}{l}\text { JAVELIN } \\
\text { NCT01772004 }\end{array}$ & $\begin{array}{l}\text { TNBC unselected for PD-L1 (68.8\% } \\
\text { had PD-L1 }{ }^{+} \text {tumors) }\end{array}$ & $\begin{array}{l}\text { Avelumab } \\
10 \mathrm{mg} / \mathrm{kg} \text { every } 2 \text { weeks }\end{array}$ & 58 & $\begin{array}{l}\text { ORR, } 5.2 \%(22.2 \% \text { in } \\
\left.\text { PD-L } 1^{+}\right) \\
\text {Median PFS, } 1.5 \text { months } \\
\text { Median OS, } 9.2 \text { months }\end{array}$ & [62] \\
\hline NCT01375842 & $\begin{array}{l}\text { Advanced TNBC unselected for PD-L1 } \\
\left(65.7 \% \text { had PD-L1+ } 1^{+} \text {tumors }\right)\end{array}$ & $\begin{array}{l}\text { Atezolizumab } 15 \text { or } 20 \mathrm{mg} / \mathrm{kg} \text {, or at a } \\
1200-\mathrm{mg} \text { flat dose, Q3W }\end{array}$ & 116 & $\begin{array}{l}\text { ORR, } 10 \%(12.7 \% \text { in } \\
\left.\text { PD-L1 }{ }^{+}\right) \\
\text {Median PFS, } 1.4 \text { months } \\
\text { by RECIST } \\
\text { Median PFS, } 1.9 \text { months } \\
\text { by irRECIST } \\
\text { Median OS, } 8.9 \text { months }\end{array}$ & [63] \\
\hline \multicolumn{6}{|c|}{ Combination of immunotherapy and chemotherapy } \\
\hline $\begin{array}{l}\text { KEYNOTE-150 } \\
\text { NCT02513472 }\end{array}$ & Advanced TNBC unselected for PD-L1 & $\begin{array}{l}\text { Eribulin } \pm \text { pembrolizumab } \\
200 \mathrm{mg} \text { Q3W }\end{array}$ & 107 & $\begin{array}{l}\text { ORR, } 26.4 \%(30.6 \% \\
\left.\text { in PD-L } 1^{+}\right) \\
\text {Median PFS, } 4.2 \text { months } \\
\text { Median OS, } 17.7 \text { months }\end{array}$ & [59] \\
\hline $\begin{array}{l}\text { IMpassion130 } \\
\text { NCT02425891 }\end{array}$ & $\begin{array}{l}\text { Untreated metastatic TNBC } \\
\text { unselected for PD-L1 }\end{array}$ & $\begin{array}{l}\text { Nab-paclitaxel } \pm \text { atezolizumab } \\
840 \text { mg Q2W }\end{array}$ & $\begin{array}{l}902 \text { ( } 451 \text { treated } \\
\text { with atezolizumab) }\end{array}$ & $\begin{array}{l}\text { ORR, } 56 \%(58.9 \% \\
\left.\text { in PD-L } 1^{+}\right) \\
\text {Median PFS, } 7.2 \text { months } \\
\text { Median PFS, } 7.5 \text { months } \\
\left(\text { PD-L } 1^{+}\right) \\
\text {Median OS, } 21.3 \text { months } \\
\text { Median OS, } 25 \text { months } \\
\left(\text { PD-L } 1^{+}\right)\end{array}$ & $\begin{array}{l}{[11,} \\
64]\end{array}$ \\
\hline
\end{tabular}

PD-L1+ expression in stroma or $\geq 1 \%$ of tumor cells by immunohistochemistry

irRECIST immune-related Response Evaluation Criteria In Solid Tumors, ORR objective response rate, OS overall survival, PD-L1 programmed death-ligand 1, PFS progression-free survival, Q2W every 2 weeks, Q3W every 3 weeks, RECIST Response Evaluation Criteria In Solid Tumors, TNBC triple-negative breast cancer

Finally, in the phase I JAVELIN trial [62], the antiPD-L1 agent avelumab produced an ORR of $5.2 \%$ in heavily pretreated metastatic TNBC patients. A trend toward a higher ORR was seen in patients with $\mathrm{PD}-\mathrm{L}^{+}$versus $\mathrm{PD}-\mathrm{L}^{-}$tumor-associated immune cells in the overall population $(16.7 \%$ vs. $1.6 \%)$ and in the TNBC subgroup (22.2\% vs. $2.6 \%)$.

As expected, a high response to single-agent anti-PD-1/ PD-L1 immunotherapy has been observed in previously untreated metastatic TNBC patients. These findings suggest that ICIs should be more active in less heavily pretreated patients, opening the door to testing these strategies in an early TNBC setting.

\section{Moving immunotherapy to early TNBC}

Previous evidence suggests that early TNBC presents with a reduced immunosuppressive phenotype compared to metastatic cases [65]. Therefore, there is increasing interest in testing immunotherapeutic strategies in both neoadjuvant and adjuvant settings. Data is available on the efficacy of ICIs in early settings obtained in stage III melanoma and non-small cell lung cancer [66-68]. In TNBC, various neoadjuvant studies are currently ongoing (Table 1 ).

Neoadjuvant trials represent an excellent in vivo laboratory to test immunotherapeutic agents and their potential combination with other drugs, including chemotherapy, targeted agents, and other immunomodulatory agents. The possibility to obtain baseline biopsies and to reassess both tumor response and changes in the tumor microenvironment at established time-points can lead to the discovery of novel biomarkers for patient stratification. Innovative findings obtained in the neoadjuvant setting could then be translated in adjuvant and metastatic settings. However, an additional important point of discussion in the neoadjuvant 
setting should be raised - when defining endpoints for immunotherapy studies, should OS and event-free survival be preferred instead of pathologic complete response? In other solid tumors, the real benefit of ICI administration is represented by an increase in OS, and therefore pathologic complete response might not be the ideal surrogate endpoint to approve these agents in the neoadjuvant setting. The selection of adequate endpoints is strongly encouraged for future clinical trials testing immunotherapy in TNBC.

Regarding the adjuvant setting, TNBC patients at high risk for relapse and who are less likely to be cured by the current standard of treatment could benefit the most by the addition of ICIs. For instance, patients with TNBC who do not achieve pathologic complete response after neoadjuvant chemotherapy have a worse prognosis, and capecitabine administration in the post-neoadjuvant setting is the only standard of care for these patients [69]. The addition of ICIs could improve cure rates in this setting; some trials are exploring this possibility (Table 1).

\section{Conclusion}

The harnessing in clinical practice of immune checkpointbased treatment has radically changed the therapeutic approaches for several tumor types. Nevertheless, until the IMpassion 130 trial, few studies had addressed immunotherapeutic strategies for the treatment of breast cancer. The IMpassion130 trial first explored the metastatic setting, with lessons being learned primarily from phase I trials. First, ICIs should be combined with other agents to improve benefit. Second, immunotherapy should be implemented in the first-line setting of metastatic treatment to improve response rates. Third, patients should be stratified according to specific biomarkers. Additionally, early-stage breast cancer appears to be even more appealing than the metastatic setting for the introduction of ICIs, both in the neoadjuvant and adjuvant settings, since primary tumors seem more immunogenic than metastatic sites. The multiple ongoing trials may shed light on breast cancer immune response biomarkers and help determine whether a multidimensional immunogram could predict efficacy better than the current PD-L1-based unidimensional immunogram.

\section{Abbreviations}

ICD: immunogenic cell death; ICls: immune checkpoint inhibitors:

ICR: immunologic constants of rejection; ITT: intent-to-treat; MDSCs: myeloidderived suppressor cells; MMR: mismatch repair; MSI: microsatellite instability; OS: overall survival; PD-L1: programmed death-ligand 1; PFS: progression-free survival; TILs: tumor-infiltrating lymphocytes; TMB: tumor mutational burden; TNBC: triple-negative breast cancer

\section{Acknowledgements}

Not applicable.

Funding

Not applicable.
Availability of data and materials

Not applicable.

\section{Authors' contributions}

GC conceived the work. GC, AM, and GV wrote and drafted the manuscript. All authors read and approved the final version of the manuscript.

\section{Authors' information}

Prof. Giuseppe Curigliano is a medical oncologist at the European Institute of Oncology (Milan, Italy) and associate professor of Medical Oncology at University of Milano (Milan, Italy). Drs. Antonio Marra and Giulia Viale are residents in Medical Oncology at the University of Milano (Milan, Italy).

Ethics approval and consent to participate

Not applicable.

\section{Consent for publication}

Not applicable.

\section{Competing interests}

GC received honoraria for speaker, consultancy or advisory roles from Roche, Pfizer, Novartis, and Seattle Genetics.

\section{Publisher's Note}

Springer Nature remains neutral with regard to jurisdictional claims in published maps and institutional affiliations.

Received: 12 February 2019 Accepted: 15 April 2019

Published online: 09 May 2019

\section{References}

1. Garrido-Castro AC, Lin NU, Polyak K. Insights into molecular classifications of triple-negative breast cancer: improving patient selection for treatment. Cancer Discov. 2019;9(2):176-98.

2. Criscitiello C, Esposito A, Trapani D, Curigliano G. Prognostic and predictive value of tumor infiltrating lymphocytes in early breast cancer. Cancer Treat Rev. 2016;50:205-7.

3. Loi S, Sirtaine N, Piette F, et al. Prognostic and predictive value of tumorinfiltrating lymphocytes in a phase III randomized adjuvant breast cancer trial in node-positive breast cancer comparing the addition of docetaxel to doxorubicin with doxorubicin-based chemotherapy: BIG 02-98. J Clin Oncol. 2013;31:860-7.

4. Dieci MV, Mathieu MC, Guarneri V, et al. Prognostic and predictive value of tumor-infiltrating lymphocytes in two phase III randomized adjuvant breast cancer trials. Ann Oncol. 2015;26:1698-704.

5. Loi S, Drubay D, Adams S, et al. Tumor-infiltrating lymphocytes and prognosis: a pooled individual patient analysis of early-stage triple-negative breast cancers. J Clin Oncol. 2019;37(7):559-69.

6. Miyashita M, Sasano $H$, Tamaki $K$, et al. Prognostic significance of tumorinfiltrating CD8+ and FOXP3+ lymphocytes in residual tumors and alterations in these parameters after neoadjuvant chemotherapy in triplenegative breast cancer: a retrospective multicenter study. Breast Cancer Res. 2015;17:124.

7. Beckers RK, Selinger Cl, Vilain R, et al. Programmed death ligand 1 expression in triple-negative breast cancer is associated with tumour-infiltrating lymphocytes and improved outcome. Histopathology. 2016;69:25-34.

8. Mittendorf EA, Philips AV, Meric-Bernstam F, et al. PD-L1 expression in triplenegative breast cancer. Cancer Immunol Res. 2014;2:361-70.

9. Cimino-Mathews A, Thompson E, Taube JM, et al. PD-L1 (B7-H1) expression and the immune tumor microenvironment in primary and metastatic breast carcinomas. Hum Pathol. 2016;47:52-63.

10. Li X, Li M, Lian Z, et al. Prognostic role of programmed death ligand-1 expression in breast cancer: a systematic review and meta-analysis. Target Oncol. 2016;11:753-61.

11. Schmid P, Adams S, Rugo HS, et al. Atezolizumab and nab-paclitaxel in advanced triple-negative breast cancer. N Engl J Med. 2018;379:2108-21.

12. Blank CU, Haanen JB, Ribas A, Schumacher TN. Cancer immunology. The 'cancer immunogram. Science. 2016;352:658-60.

13. Patel SP, Kurzrock R. PD-L1 expression as a predictive biomarker in cancer immunotherapy. Mol Cancer Ther. 2015;14:847-56. 
14. Gibney GT, Weiner LM, Atkins MB. Predictive biomarkers for checkpoint inhibitor-based immunotherapy. Lancet Oncol. 2016;17:e542-51.

15. Reck M, Rodriguez-Abreu D, Robinson AG, et al. Pembrolizumab versus chemotherapy for PD-L1-positive non-small-cell lung cancer. N Engl J Med 2016;375:1823-3.

16. Buttner R, Gosney JR, Skov BG, et al. Programmed death-ligand 1 immunohistochemistry testing: a review of analytical assays and clinical implementation in non-small-cell lung cancer. J Clin Oncol. 2017;35:3867-76.

17. Kwa MJ, Adams S. Checkpoint inhibitors in triple-negative breast cancer (TNBC): where to go from here. Cancer. 2018;124:2086-103.

18. Emens LA, Loi S, Rugo HS, et al. Abstract GS1-04: IMpassion130: efficacy in immune biomarker subgroups from the global, randomized, double-blind, placebo-controlled, phase III study of atezolizumab + nab-paclitaxel in patients with treatment-naïve, locally advanced or metastatic triple-negative breast cancer. Cancer Res. 2019;79:GS1-04

19. Ribas A, Hu-Lieskovan S. What does PD-L1 positive or negative mean? J Exp Med. 2016;213:2835-40.

20. Loi S, Adams S, Schmid P, et al. LBA13 relationship between tumor infiltrating lymphocyte (TIL) levels and response to pembrolizumab (pembro) in metastatic triple-negative breast cancer (mTNBC): results from KEYNOTE-086. Ann Oncol. 2017;28(Suppl 5):mdx440.005.

21. Loi S, Schmid P, Cortés J, et al. Relationship between tumor infiltrating lymphocytes (TILs) and response to pembrolizumab (Pembro)+ chemotherapy (Chemo) as neoadjuvant treatment (NAT) for triple-negative breast cancer (TNBC): phase lb KEYNOTE-173 trial. Proceedings of the 2018 San Antonio Breast Cancer Symposium; 2018 Dec 4-8; San Antonio, TX. Philadelphia (PA): AACR; Cancer Res 2019;79(4 Suppl):Abstract nr P3-10-09.

22. Savas $P$, Virassamy $B, Y e ~ C$, et al. Single-cell profiling of breast cancer $T$ cells reveals a tissue-resident memory subset associated with improved prognosis. Nat Med. 2018;24:986-93.

23. Hendrickx W, Simeone I, Anjum S, et al. Identification of genetic determinants of breast cancer immune phenotypes by integrative genomescale analysis. Oncoimmunology. 2017;6:e1253654.

24. Loi S, Dushyanthen S, Beavis PA, et al. RAS/MAPK activation is associated with reduced tumor-infiltrating lymphocytes in triple-negative breast cancer: therapeutic cooperation between MEK and PD-1/PD-L1 immune checkpoint inhibitors. Clin Cancer Res. 2016;22:1499-509.

25. Criscitiello C, Bayar MA, Curigliano G, et al. A gene signature to predict high tumor-infiltrating lymphocytes after neoadjuvant chemotherapy and outcome in patients with triple-negative breast cancer. Ann Oncol. 2018;29:162-9.

26. Kandoth C, McLellan MD, Vandin F, et al. Mutational landscape and significance across 12 major cancer types. Nature. 2013;502:333-9.

27. Goodman AM, Kato S, Bazhenova L, et al. Tumor mutational burden as an independent predictor of response to immunotherapy in diverse cancers. Mol Cancer Ther. 2017;16:2598-608.

28. Rizvi NA, Hellmann MD, Snyder A, et al. Cancer immunologyMutational landscape determines sensitivity to PD-1 blockade in non-small cell lung cancer. Science. 2015;348:124-8.

29. Hellmann MD, Ciuleanu TE, Pluzanski A, et al. Nivolumab plus ipilimumab in lung cancer with a high tumor mutational burden. N Engl J Med. 2018;378: 2093-104.

30. Samstein RM, Lee $\mathrm{CH}$, Shoushtari AN, et al. Tumor mutational load predicts survival after immunotherapy across multiple cancer types. Nat Genet. 2019; 51:202-6.

31. Thomas A, Routh ED, Pullikuth A, et al. Tumor mutational burden is a determinant of immune-mediated survival in breast cancer. Oncoimmunology. 2018;7:e1490854

32. Cortes-Ciriano I, Lee S, Park WY, et al. A molecular portrait of microsatellite instability across multiple cancers. Nat Commun. 2017:8:15180.

33. Bonneville R, Krook MA, Kautto EA, et al. Landscape of microsatellite instability across 39 cancer types. JCO Precis Oncol. 2017;2017. https://doi. org/10.1200/PO.17.00073.

34. Le DT, Uram JN, Wang H, et al. PD-1 blockade in tumors with mismatchrepair deficiency. N Engl J Med. 2015;372:2509-20.

35. Le DT, Durham JN, Smith KN, et al. Mismatch repair deficiency predicts response of solid tumors to PD-1 blockade. Science. 2017:357:409-13.

36. Obeid E, Ellerbrock A, Handorf $E$ et al. Distribution of microsatellite instability, tumor mutational load, and PD-L1 status in molecularly profiled invasive breast cancer. Proceedings of the 2017 San Antonio Breast Cancer Symposium; 2017 Dec 5-9; San Antonio, TX. Philadelphia (PA): AACR; Cancer Res 2018;78(4 Suppl):Abstract nr PD6-03.
37. Foulkes WD, Smith IE, Reis-Filho JS. Triple-negative breast cancer. N Engl J Med. 2010;363:1938-48.

38. Robson M, Im SA, Senkus E, et al. Olaparib for metastatic breast cancer in patients with a germline BRCA mutation. N Engl J Med. 2017;377: 523-33.

39. Lord CJ, Ashworth A. BRCAness revisited. Nat Rev Cancer. 2016;16:110-20.

40. Nolan E, Savas P, Policheni AN, et al. Combined immune checkpoint blockade as a therapeutic strategy for BRCA1-mutated breast cancer. Sci Transl Med. 2017;9(393).

41. Mouw KW, Goldberg MS, Konstantinopoulos PA, D'Andrea AD. DNA damage and repair biomarkers of immunotherapy response. Cancer Discov. 2017:7:675-93.

42. Vinayak S, Tolaney SM, Schwartzberg LS, et al. TOPACIO/Keynote-162: niraparib + pembrolizumab in patients (pts) with metastatic triple-negative breast cancer (TNBC), a phase 2 trial. J Clin Oncol. 2018;36:1011.

43. Aigner J, Marmé F, Smetanay K, et al. Nab-paclitaxel monotherapy as a treatment of patients with metastatic breast cancer in routine clinical practice. Anticancer Res. 2013:33:3407-13.

44. Kroemer G, Senovilla L, Galluzzi L, et al. Natural and therapy-induced immunosurveillance in breast cancer. Nat Med. 2015;21:1128-38.

45. Pol J, Vacchelli E, Aranda F, et al. Trial watch: immunogenic cell death inducers for anticancer chemotherapy. Oncoimmunology. 2015;4:e1008866.

46. Heinhuis KM, Ros W, Kok M, et al. Enhancing anti-tumor response by combining immune checkpoint inhibitors with chemotherapy in solid tumors. Ann Oncol. 2019;30(2):219-35.

47. Galluzzi L, Buque A, Kepp O, et al. Immunogenic cell death in cancer and infectious disease. Nat Rev Immunol. 2017;17:97-111.

48. Demaria S, Volm MD, Shapiro RL, et al. Development of tumor-infiltrating lymphocytes in breast cancer after neoadjuvant paclitaxel chemotherapy. Clin Cancer Res. 2001;7:3025-30.

49. Kodumudi KN, Woan K, Gilvary DL, et al. A novel chemoimmunomodulating property of docetaxel: suppression of myeloid-derived suppressor cells in tumor bearers. Clin Cancer Res. 2010;16:4583-94.

50. Roselli M, Cereda V, di Bari MG, et al. Effects of conventional therapeutic interventions on the number and function of regulatory $T$ cells. Oncoimmunology. 2013;2:e27025.

51. Li JY, Duan XF, Wang LP, et al. Selective depletion of regulatory T cell subsets by docetaxel treatment in patients with nonsmall cell lung cancer. J Immunol Res. 2014;2014:286170.

52. Ghiringhelli F, Menard C, Puig PE, et al. Metronomic cyclophosphamide regimen selectively depletes CD4+CD25+ regulatory $T$ cells and restores $T$ and NK effector functions in end stage cancer patients. Cancer Immunol Immunother. 2007;56:641-8.

53. Kwa M, Li X, Novik Y, et al. Serial immunological parameters in a phase II trial of exemestane and low-dose oral cyclophosphamide in advanced hormone receptor-positive breast cancer. Breast Cancer Res Treat. 2018;168:57-67.

54. Homma Y, Taniguchi $K$, Nakazawa M, et al. Changes in the immune cell population and cell proliferation in peripheral blood after gemcitabine-based chemotherapy for pancreatic cancer. Clin Transl Oncol. 2014;16:330-5.

55. Vincent J, Mignot G, Chalmin F, et al. 5-fluorouracil selectively kills tumorassociated myeloid-derived suppressor cells resulting in enhanced $T$ celldependent antitumor immunity. Cancer Res. 2010;70:3052-61.

56. Jackaman C, Majewski D, Fox SA, et al. Chemotherapy broadens the range of tumor antigens seen by cytotoxic CD8(+) T cells in vivo. Cancer Immunol Immunother. 2012;61:2343-56.

57. Nio $Y$, Hirahara $N$, Minari $Y$, et al. Induction of tumor-specific antitumor immunity after chemotherapy with cisplatin in mice bearing MOPC-104E plasmacytoma by modulation of MHC expression on tumor surface. Anticancer Res. 2000;20:3293-9.

58. Huang $X$, Cui S, Shu Y. Cisplatin selectively downregulated the frequency and immunoinhibitory function of myeloid-derived suppressor cells in a murine B16 melanoma model. Immunol Res. 2016;64:160-70.

59. Tolaney S, Kalinsky K, Kaklamani V, et al. Phase 1b/2 study to evaluate eribulin mesylate in combination with pembrolizumab in patients with metastatic triple-negative breast cancer. Cancer Res. 2018;78(abstr):PD6-PD13.

60. Nanda $R$, Chow LQ, Dees EC, et al. Pembrolizumab in patients with advanced triple-negative breast cancer: phase Ib KEYNOTE-012 study. J Clin Oncol. 2016:34:2460-7.

61. Adams S, Schmid P, Rugo HS, et al. Pembrolizumab monotherapy for previously treated metastatic triple-negative breast cancer: cohort a of the phase 2 KEYNOTE-086 study. Ann Oncol. 2019;30(3):397-404. 
62. Dirix LY, Takacs I, Jerusalem G, et al. Avelumab, an anti-PD-L1 antibody, in patients with locally advanced or metastatic breast cancer: a phase 1b JAVELIN solid tumor study. Breast Cancer Res Treat. 2018;167:671-86.

63. Emens $L A$, Cruz C, Eder JP, et al. Long-term clinical outcomes and biomarker analyses of atezolizumab therapy for patients with metastatic triple-negative breast cancer: a phase 1 study. JAMA Oncol. 2019:5(1):74-82.

64. Emens LA, Loi S, Rugo HS, et al. Abstract GS1-04: IMpassion130: efficacy in immune biomarker subgroups from phase III study of atezolizumab + nabpaclitaxel in patients with treatment-naïve, locally advanced or metastatic TNBC. Cancer Res 2019;79(4 Suppl):Abstract nr GS1-04.

65. Gil Del Alcazar CR, Huh SJ, Ekram MB, et al. Immune escape in breast cancer during in situ to invasive carcinoma transition. Cancer Discov. 2017;7:1098-115.

66. Eggermont AM, Chiarion-Sileni V, Grob JJ, et al. Prolonged survival in stage III melanoma with ipilimumab adjuvant therapy. N Engl J Med. 2016;375:1845-55.

67. Weber J, Mandala M, Del Vecchio M, et al. Adjuvant nivolumab versus ipilimumab in resected stage III or IV melanoma. N Engl J Med. 2017;377:1824-35.

68. Antonia SJ, Villegas A, Daniel D, et al. Overall survival with durvalumab after chemoradiotherapy in stage III NSCLC. N Engl J Med. 2018;379:2342-50.

69. Masuda N, Lee SJ, Ohtani S, et al. Adjuvant capecitabine for breast cancer after preoperative chemotherapy. N Engl J Med. 2017;376(22):2147-59.

Ready to submit your research? Choose BMC and benefit from:

- fast, convenient online submission

- thorough peer review by experienced researchers in your field

- rapid publication on acceptance

- support for research data, including large and complex data types

- gold Open Access which fosters wider collaboration and increased citations

- maximum visibility for your research: over $100 \mathrm{M}$ website views per year

At $\mathrm{BMC}$, research is always in progress.

Learn more biomedcentral.com/submissions 